\title{
The study of prescriptive and descriptive models of decision making
}

\author{
Prof. Ashok A. Divekar \\ Indira College of Engineering and \\ Management, \\ PUNE, INDIA
}

\author{
Prof. Sunita Bangal \\ Indira Institute of Management, \\ PUNE, INDIA
}

\author{
Prof. Sumangala D. \\ Indira Institute of Management, \\ PUNE, INDIA
}

\begin{abstract}
The field of decision making can be loosely divided into two parts: the study of prescriptive models and the study of descriptive models. Prescriptive decision scientists are concerned with prescribing methods for making optimal decisions. Descriptive decision researchers are concerned with the bounded way in which the decisions are actually made.

The statistics courses treat risk from a prescriptive, by suggesting rational methods. This paper brings out the work done by many researchers by examining the psychological factors that explain how managers deviate from rationality in responding to uncertainty.
\end{abstract}

Keywords- Expected Value; Prospect; expected-value rule; riskaverse.

\section{INTRODUCTION}

Most management students are formally taught the concept of risk and uncertainty (or probability) in microeconomics and for statistics courses. These courses typically treat risk by describing rational methods for making decisions involving risk i. e. probability of gain. This paper extends this perspective by examining the psychological factors that tell us how managers deviate from rationality in responding to uncertainty. Max Bazerman has examined how subtle aspects in the presentation of information, called as the "framing" of information, can significantly impact decision making [1]. Throughout the literature on decision making, it is many times suggested that intuitions about risk routinely take over the minds of decision-makers, leading to decisions which deviate from rationality. This is because managers do not understand the nature of uncertainty and the effects of framing. However, uncertainty is a managerial fact of life.

Let us consider two situations which are very common and representative of managers' dilemma.

\section{A. Situation 1:}

A company is faced with a suit from a hostile social group of consumers. The organization believes that it is innocent but it also realizes that the court may not have the same opinion.

1) Option A: Settle out of the court and accept a sure loss of Rupees 25,000,000

2) Option B: Go to the court expecting a fifty percent probability of a Rs. 50,000,000 loss. Alternatively, the same situation can be defined or framed in this way.
3) Option C: Settle out of court and save Rs. 25,000,000 that could be lost in court, or

4) Option D: Go to court expecting a fifty percent probability of saving Rs.50, 000,000.

5) Options $A \& B$ are framed negatively- that is, in terms of possible losses. Option C\&D are framed positively that is, in term of possible gains.

$\mathrm{A}$ is equivalent to $\mathrm{C}$, and $\mathrm{B}$ is equivalent to $\mathrm{D}$. A consistent decision maker would choose $A \& C$, or $B \& D$. choosing $A \& D$, or $\mathrm{B} \& \mathrm{C}$ would be inconsistent.

\section{B. Situation 2 :}

When a test was conducted on MBA students, surprisingly, over eighty percent selected option B in the first situations, and option $\mathrm{C}$ in the second situations [1]. Research has shown that individuals tend to take risks concerning choices framed in terms of possible losses- even though both sets of choice are objectively the same. Thus, decision makers are systematically affected by the way in which information is presented. Dawes argues that humans want to "know now" in situations containing inherent uncertainty [2]. He claims that the need to do away with uncertainty frequently leads people to take too much credit for successes and too much blame for failures.

In real world, most people are not consistent in their approach to risk. When Slavic compared the scores of eightytwo people on nine different measures of risk taking, he found no evidence to suggest that a generalizable risk taking trait exits [3]. People who are aggressive in one situation may be conservative in another. The conservative financial analyst may let himself break loose on weekends. The habitual gambler may be conservative in caring for his health or making rules for his children. Slovic found that intelligence was not related to a risk - taking level [3].

When a test was conducted on MBA students, surprisingly, over eighty percent selected option B in the first situations, and option $\mathrm{C}$ in the second situations [1]. Research has shown that individuals tend to take risks concerning choices framed in terms of possible losses- even though both sets of choice are objectively the same. Thus, decision makers are systematically affected by the way in which information is presented. Dawes argues that humans want to "know now" in situations containing inherent uncertainty [2]. He claims that the need to do away with uncertainty frequently leads people to take too much credit for successes and too much blame for failures. 
In real world, most people are not consistent in their approach to risk. When Slavic compared the scores of eightytwo people on nine different measures of risk taking, he found no evidence to suggest that a generalizable risk taking trait exits [3]. People who are aggressive in one situation may be conservative in another. The conservative financial analyst may let himself break loose on weekends. The habitual gambler may be conservative in caring for his health or making rules for his children. Slovic found that intelligence was not related to a risk - taking level [3].

As managers, we are constantly faced with decisions that will lead to uncertain outcomes [4]. Many of this risky decision are crucial, involving issues like jobs, safety, product reliability, and sometimes organizational existence. As such, managers should understand risk, which will enhance their ability to make and evaluate decision in uncertain situations. Managers will make better decisions by accepting that uncertainty exists and learning how to think systematically in risky situations. Dawes describes,

"Imagine a life without uncertainty - - - - - - -Imagine how dull life would be if everything can be predicted with great accuracy. Life would be intolerable - . - . - No hope no challenge!" [5].

We know that the individuals are typically neither rational nor consistent in making judgments under uncertainty. We all know that the rational decision-making process includes

- Specifying the problem.

- Identifying all factors.

- Weighting Factors.

- Identifying all alternatives.

- Rating alternatives on each factor.

- Choosing the optimal alternative.

The rational model does not tell us how to rate alternatives when the outcome on a particular factor is uncertain.

Let us understand two concepts: Probability and Expected value.

\section{A. Probability:}

The concept of probability tells us the likelihood that any particular outcome will occur. A probability of 1.0 represents certainty that an event will occur. A probability of zero represents certainty that an event will not occur.

\section{B. Expected Value:}

Calculating the expected value of any alternative involves weighting all potential outcomes associated with that alternative by their probabilities and summing them. One simple rule for making decision is to always select the alternative with the highest expected value. Consider following scenarios:

You can

a) Have Rs. 10,000,000 for sure (expected value $=R s$. $10,000,000)$ or b) Flip an honest coin where you get Rs. 24,000,000, if a heads occurs but get nothing if a tail occurs (expected value = Rs. 12,000,000).

An expected value decision rule would pick. (b)

What would you do?

You are being sued for Rs. 100,000 and estimate a $50 \%$ chance of losing the case (expected value = Rs. $-50,000$ ).

However, the other side is willing to accept an out-of-court settlement of Rs. 40,000 (expected value $=-40,000$ ), ignoring attorney fees, court costs, and so on.

a) Would you fight the case?

b) Settle out of court?

An expected value decision rule would tell you to settle out of court. Most people would take a) in both cases. This clearly indicates that a number of situations exist in which people do not follow an expected-value rule.

\section{RISK CONSIDERATIONS}

Let us try to understand the concept of a "certainty equivalent". A certainty equivalent establishes the certain value that would make a decision maker indifferent between an uncertain event and that certain value. For example if you had an opportunity to accept a $50 \%$ chance of obtaining Rs. 100,000 , what would be the certain amount that would make you indifferent between the $50 \%$ chance of Rs. 100,000 and that amount. Rs. 10,000? Rs. 40,000? This is your certainty equivalent to a $50 \%$ chance of Rs. 100,000. For most people, this amount is far less than the expected value of the bet of Rs. 50,000 .

An individual who has a certainty equivalent for an uncertain event that is equal to the expected value of the uncertain payoff is "risk neutral", with regard to that decision.

For example, if your certainty equivalent in the previous paragraph was Rs. 50,000, you would be risk neutral, concerning that choice thus, risk neutrality is synonymous with using an expected -value decision rule. An individual with a certainty equivalent for an uncertain event that is less than the expected value of that uncertain payoff is "risk averse", with regard to that decision. If your certainty equivalent in the previous paragraph was Rs. 40,000, then you are risk averse, since you are willing to take an expected value reduction of Rs. 10,000 to avoid the risk associated the uncertain event. Although it is unlikely in the situation described in the previous paragraph, an individual with a certainty equivalent for an uncertain event that is more than the expected value for that uncertain payoff is "risk seeking" with regard to that decision. If your certainty equivalent was Rs. 70,000, you are "risk seeking", since you are demanding extra expected value of Rs. 20,000 to forego the risk. Thus you seek risk, holding the expected value constant.

When decision makes act in a risk-averse or risk seeking manner, they make decisions that often exclude the maximizing of expected value. To explain departures from the expected value decision rule, Daniel Bernoulli first suggested replacing the criterion of expected monetary value with the criterion of expected utility [1]. Expected utility theory suggests that an 
each level of an outcome is associated with some degree of pleasure, or net benefit, called utility. The expected utility of an uncertain choice is the weighted sum of the utilities of its outcomes, each multiplied by its probability while an expected value approach to decision-making would treat Rs. 100,000 as being worth twice as much as Rs. 50,000, a gain of Rs. 100,000 does not always create twice as much expected utility as a gain of Rs. 50,000. Most individuals do not obtain as much utility from the second Rs. 50,000 as they did from the first Rs. 50,000 . Thus under expected utility theory, the decision maker is predicted to select the option with the highest expected utility, regardless of whether that choice has the highest expected value.

Further, according to expected- utility theory, individuals identity outcomes in terms their overall wealth and the additional wealth they would have as a result of each alternative outcome. Kahneman and Tversky's prospect theory refutes this aspect of expected-utility theory [6]. They argue that each decision is approached independently.

\section{THE FRAMING OF INFORMATION}

\section{Consider the following problem [7].}

A large car manufacturer has recently been hit with a number of economic difficulties, and it appears as if three plants need to be closed and 6000 employees laid off. The vice president of production has been exploring alternative ways to avoid this crisis. He has developed two plans:

\section{A. Plan A:}

This plan will save one of the three plants, and 2000 jobs.

\section{B. Plan B:}

This plan has a $1 / 3$ probability of saving all three plants and all 6000 jobs, but has a $2 / 3$ probability of saving no plants and no jobs.

Which plan would you select?

There are number of things which we might consider in evaluating these options like impact on union, moral of retained employees, and the values of the corporation. While all these questions are important, a more fundamental question underlies the subjective situation and the resulting decision.

Now consider this problem, replacing the choices with the following choices:

\section{Plan C:}

This plan will result in the loss of two of three plants and 4000 jobs.

\section{Plan D:}

This plan has a $2 / 3$ probability of resulting in the loss of all three plants and all 6000 jobs, but has a $1 / 3$ probability of loosing no plants and no jobs.

Which plan would you select?

Close examination of the two sets of alternative plans finds them to be objectively the same. Plan A and Plan C offer the same objective outcome. Plans B and D are objectively identical.
However, the investigation demonstrates that most management graduates choose Plan A in the first set and Plan $\mathrm{D}$ in the second set [7]. Changing the description of the outcomes from jobs and plants saved to jobs and plants lost is responsible to shift choice from risk-averse to risk seeking behavior.

This shift is consistent with the available literature that show that individuals treat risks concerning perceived gains (saving plants, jobs) differently from risks concerning perceived losses (loosing plants, jobs) [8][9][10]. In an attempt to explain these common and systematic deviations from rationality, Kahneman and Tversky developed "Prospect Theory" [8]. This theory suggests the following:

1) Rewards and losses are evaluated relative to a neutral reference point.

2) Potential outcomes are expressed as gains (such as jobs and plants saved) or losses (jobs and plants lost) relative to this fixed, neutral reference point.

3) The choices that people make are formed based on the resulting change in asset position as assessed by $S$ - shaped value function. (See Fig. 1).

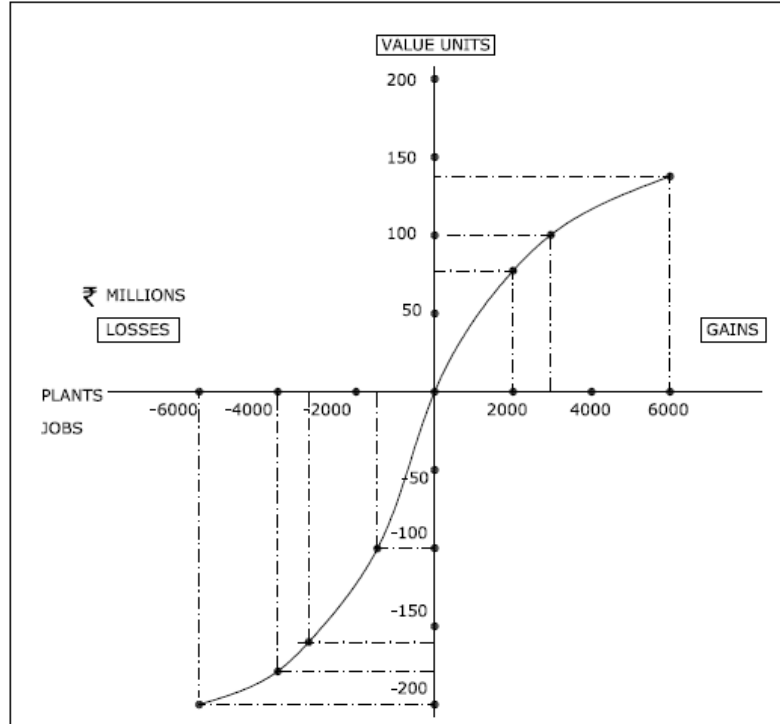

Fig 1. Hypothetical value function accounting for framing

Figure 1. Hypothetical Value function

On this graph, the $\mathrm{X}$ - axis represents the nominal units gained or lost, and the $\mathrm{Y}$ - axis represents the units of utility associated with varying levels of gain or loss. This figure shows that decision makers tends to avoid risk concerning gains and seek risk concerning losses. For example, the $\mathrm{S}-$ shaped value function implies that most individuals would choose a Rs. $10,000,000$ sure gain over a $50 \%$ chance of getting a Rs. 20,000,000 gain, since the utility placed on Rs. $20.000,000$ is not twice as great as the value placed on Rs. $10,000,000$, but that most individuals would choose a $50 \%$ chance of a Rs. 20,000,000 loss over a sure loss of Rs. $10,000,000$, since the negative value placed on Rs. $20,000,000$ is not twice as great as the negative value placed on Rs. $10,000,000$. 


\section{CONCLUSION}

An important outcome of this theory is that the way in which the problem is "framed" or presented, can dramatically change the perceived neutral point of the question. In the above problem, if the problem is framed in terms of losing jobs and plants (Plan C and Plan D), the current position of having three plants open forms the neutral reference point, and risk seeking behavior results. The negative value placed on the loss of three plants and 6000 jobs is usually perceived as not being three times as negative as losing one plant and 2000 jobs. However, if the problem is framed in terms of saving jobs and plants (Plan A and Plan B) the potential disaster of losing everything becomes the neutral reference point, leading to riskaverse behavior.

A second characteristic of our decision making processes identified by prospect theory is that our response to loss is more extreme than our response to gain. According to Fig. 1, the pain associated with loosing Rs. $\mathrm{X}$ is generally greater than the pleasure associated with winning the same amount.

Prospect theory identifies a third way in which our decision making processes deviate from expected utility theory. It states that we tend to overweight the probability of two probability events and underweight the probability of moderate and high probability events.

Prospect theory represents the most important advance in our understanding of behavioral decision-making processes. Apart from "framing" gains and losses, the context in which outcomes occur also affects our consistencies in interpreting outcomes. Similarly, the summing, or aggregation, of a number of outcomes evokes different responses.
We put a higher value on loosing personal time than we do on gaining more personal time. We want good outcomes now, but bad outcomes later. Postponing a good outcome results in a greater loss of perceived utility than not postponing an equivalent bad outcome.

We should now be able to identify situations in which we currently adopt a particular frame. If we understand and apply this knowledge, the consistency and quality of our decision will improve.

\section{REFERENCES}

[1] Bazerman, Max H: Judgment in managerial decision making: John Wiley \& Sons.

[2] Dawes, R.M. Rational choice in an uncertain world: New York: Harcourt Brace Jovanovich.

[3] Slovic, P.: Information processing, situation specificity, and the generality of risk-taking behavior: Journal of personality \& social psychology.

[4] MacCrimmon, K.R. and Wehrung D. A. Taking risks: New York Free Press.

[5] Dawes, R. M.: Rational choice in an uncertain world: New York: Harcourt Brace Jovanovich.

[6] Kahneman D., and Tversky A.: Prospect theory: An analysis of decision under risk: Econometrica.

[7] Miller, P. M. and Fagley, N. S.: The effects of framing, problem variations, and providing rationale on choice.

[8] Bazerman, Max H.: The relevance of Kahneman \& Tversky's concept of framing to organizational behavior: Journal of management.

[9] Tversky, A. and Kahneman, D.: Rational choice and the framing of decision: Journal of business.

[10] Thaler, R.: Toward a positive theory of consumer choice: Journal of economic behavior \& organization. 